\title{
Prioritising action on alcohol for health and development
}

\author{
Despite the existence of cost effective interventions to reduce harmful use of alcohol, many \\ countries are not giving it the attention it deserves, say Dag Rekve and colleagues
}

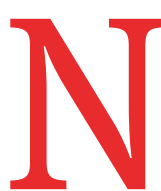

on-communicable diseases (NCDs)-mainly cardiovascular diseases, diabetes, cancers, chronic respiratory diseases, and mental health conditions-are now the dominant cause of death and disabilities across the world, with alcohol use recognised as a leading risk factor. ${ }^{12}$ Alcohol use is also linked to violence, injuries, and infectious diseases, ${ }^{3}$ causing substantial economic losses and social harms, including harms to others. ${ }^{45}$ The health, social, and economic risks associated with alcohol consumption go beyond NCDs and justify greater public health and wider development action. $^{3}$

Governments have made commitments to reduce the harmful use of alcohol through the World Health Organization global strategy on alcohol use, WHO and United Nations resolutions, and the 2030 sustainable development agenda. ${ }^{6-9}$ Although governments have endorsed a set of proved, cost effective, and feasible interventions to tackle the harmful use of alcohol, ${ }^{10}$ progress in the formulation and implementation of national and local alcohol control measures has been uneven. ${ }^{310}$ Meeting global, regional, and national health and development goals will

\section{KEY MESSAGES}

- Harmful use of alcohol is among the leading risk factors for the global burden of disease

- Cost effective strategies to reduce the harmful use of alcohol exist and should be more widely used, with an equity focus

- Global and regional policy frameworks and guidance can help countries to develop national and local alcohol policies and programmes

- The alcohol industry should not be allowed to influence public health policy

- Civil society can advocate for action and hold policy makers and government agencies to account require greater global and national action to formulate effective policies that reduce the harmful use of alcohol, commitment to enhance and accelerate the implementation and monitoring of existing policies, and prevention of industry interference. ${ }^{311-13}$

\section{Need for action on alcohol}

Scientific consensus is growing that there is a robust public health case for policy makers to implement WHO's recommended interventions to reduce the harmful use of alcohol. ${ }^{21415}$ WHO estimates that harmful use of alcohol contributed to three million deaths (5.3\% of all deaths) in 2016, of which 1.7 million were from NCDs. Overall, harmful use of alcohol accounted for 5.1\% of the global burden of disease and $4.2 \%$ of the NCD burden in 2016 . $^{3}$

Alcohol related harm affects all countries. Although the European region has the highest total per capita consumption of alcohol and the highest share of all deaths attributable to alcohol compared with other risk factors for the global burden of disease, low and middle income countries, and especially Africa, have the highest age standardised attributable deaths per 100000 people, indicating greater harm per litre of alcohol consumed than in wealthier countries (fig 1). ${ }^{3}$

Alcohol accounts for $7.1 \%$ and $2.2 \%$ of the global burden of disease for men and women respectively and is the leading risk factor for premature mortality and disability among those aged 15 to 49 years, accounting for $10 \%$ of all deaths in this age group. ${ }^{2}$ People of low socioeconomic status are disproportionately affected, underlining the inequity perspective in alcohol related harm. ${ }^{1617}$

Recent modelling forecasts that global targets to reduce harmful use of alcohol will not be met. ${ }^{18}$ The current rates of alcohol consumption and population growth are two important considerations when assessing the future harms of alcohol. In $2016,43 \%$ of the world's population aged $\geq 15$ years had consumed alcohol in the previous 12 months. ${ }^{3}$ This equates to 2.3 billion people. In Africa, $32 \%$ of the adult population currently consumes alcohol, and the population is predicted to grow by 1.2 billion people by $2050 .{ }^{19}$ Without action Africa could see an increase in both the absolute number and proportion of people consuming alcohol, the amount drunk per capita, and heavy episodic drinking. ${ }^{18}$ There are similar challenges in other parts of the world-for example, South East Asia has seen a $29 \%$ increase in alcohol consumption per capita since $2010 .^{3}$

The WHO global alcohol strategy, endorsed by the World Health Assembly in $2010,{ }^{9}$ provides guidance on formulating and implementing effective national alcohol policies. In 2017, the World Health Assembly endorsed three effective interventions that cost $\leq \$ 100$ ( $€ 78$; $€ 90)$ per disability adjusted life year (DALY) averted in low and middle income countries. These so called "best buys" are increasing excise taxes on alcoholic beverages, comprehensive restrictions on alcohol advertising, and restrictions on sales of alcohol.

Implementation of the three best buys would result in a return on investment of $\$ 9$ for every $\$ 1$ invested. ${ }^{20}$ Over 50 years, a $20 \%$ global increase in alcohol taxes alone could avert nine million premature deaths. ${ }^{21}$ Revenues from excise tax, alcohol company taxes, and licensing fees could also help cover, or even meet, the costs of a comprehensive alcohol control programme, the prevention and treatment of disorders caused by alcohol use, as well as contributing to the funding of other health and development priorities. A 20\% increase in the price of alcohol through higher taxes could accumulate as much as \$9tn in increased revenues globally over 50 years. $^{21}$

The World Health Assembly also endorsed measures against drink driving (including setting legal limits for blood alcohol concentration) and the provision of brief psychosocial interventions for people with hazardous or harmful alcohol use..$^{101222}$

To support countries in scaling up implementation of these five cost effective 


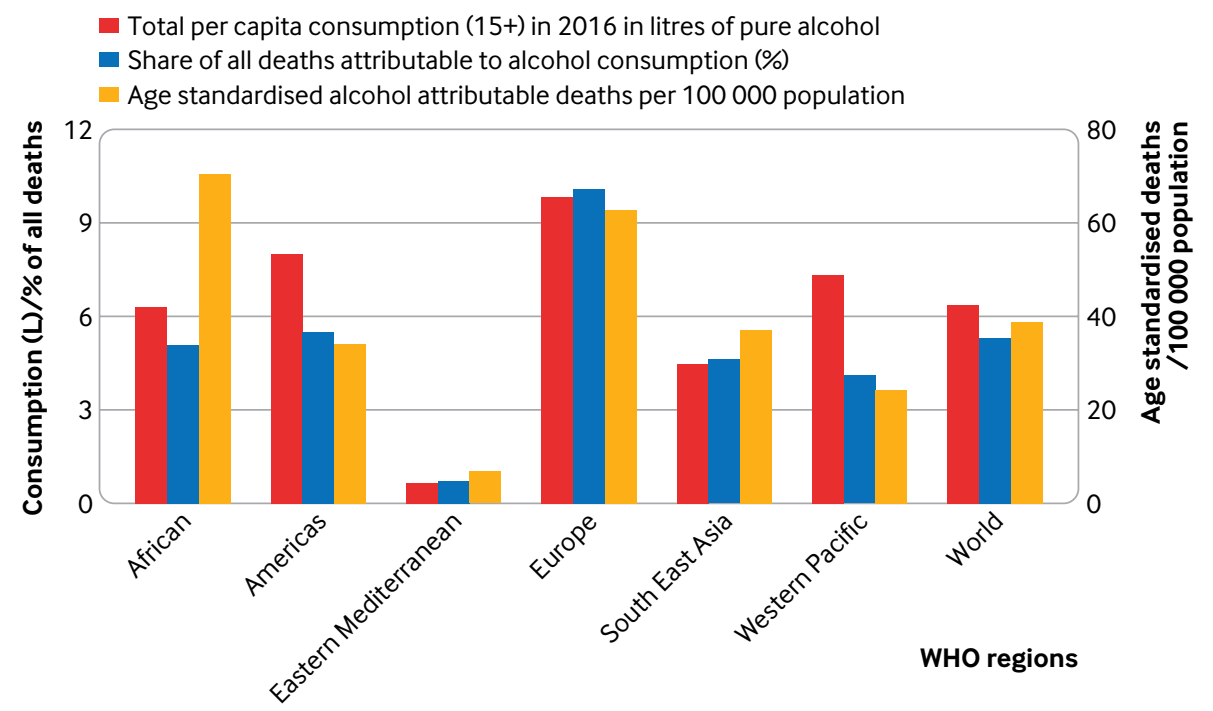

interventions, a new WHO led initiative called SAFER was launched in 2018 (box 1).

\section{Lack of implementation}

Some countries have shown the benefits of implementing evidence based, cost effective, and high impact policies. ${ }^{23}$ The Russian Federation, for example, implemented alcohol control measures in 2003. By 2016 recorded consumption of alcohol had fallen by $40 \%$ and unrecorded consumption by $48 \% .^{3}$ Over the same period all-cause mortality dropped by $39 \%$ in men and $36 \%$ in women, with the sharpest decline in causes of death linked to alcohol consumption. ${ }^{24}$

Nevertheless, most countries, particularly low and middle income countries, have not implemented a comprehensive set of alcohol policies. ${ }^{3}$ No low income country has reported increasing the resources for implementing alcohol policy since the WHO global alcohol strategy was adopted in 2010. In addition, many countries are failing to implement the best buys, with low and middle income countries more likely to have weaker policies. ${ }^{325}$ The 2018 WHO global status report on alcohol and health highlights problems with all of the five most cost effective measures.

Although physical access to alcohol is proved to reduce alcohol related harms, less than one third of countries have regulations on outlet density or days of sale. Some countries, mainly low and middle income countries in Africa, still have no legal minimum purchase age.

Most countries have some restrictions on alcohol advertising, but marketing restrictions on the internet and social media are generally further behind, suggesting that regulation continues to lag behind technological innovations and e-commerce, including rapidly developing new delivery systems. Most of the countries that reported no restrictions across all media types were located in the African or Americas regions.

Increasing the price of alcohol is the single most effective strategy to reduce and prevent alcohol related harm. Although 95\% of reporting countries implement alcohol excise taxes, few use such taxes as a public health policy to reduce consumption and less than half use price strategies such as adjusting taxes to keep up with inflation and income levels, imposing minimum pricing policies, or banning selling below cost or volume discounts.

Drink driving legislation is common (155 countries had some type of legislation), but less than half of low income countries had set blood alcohol limits for driving. The limits were also likely to be higher $(\leq 0.05 \%$ in $82 \%$ of high income countries compared with $0.08 \%$ in $57 \%$ of the low income countries with established limits). Enforcement of these limits was low in low and middle income countries.

Finally, despite the effectiveness of brief psychosocial interventions in primary care settings, scaling them up continues to be a challenge in most countries given the limited resources for capacity building and monitoring of health systems. The estimated treatment coverage for alcohol use disorders is also low across the world, and global standardised indicators are being developed to measure treatment coverage for alcohol and other substance use disorders.

\section{Barriers to implementation}

Several of the most cost effective interventions require legislative or regulatory action- for example, taxes, marketing restrictions, regulations on availability, including sale to minors and licensing, and road traffic laws. An effective programme requires broad political commitment and dedicated and sustained financing at national and local level. Regulatory approaches need to be supported by effective enforcement.

Policy coherence across government is crucial, and implementation of these comprehensive measures requires multisectoral collaboration. For example, tax policy requires leadership from ministries of finance, and drink driving prevention requires transportation and law enforcement authorities. Civil society also has an important role, acting as advocates, allies, and independent monitors of policy implementation and interference by vested interests.

Strong monitoring and evaluation is important to track progress and ensure accountability. ${ }^{9}$ Indicators need to be further refined or developed to cover sales, consumption, health and social harms, economic impact, policy implementation, and industry practices. Countries should publish regular reports on progress.

Since all the most cost effective interventions restrict commercial activity, governments have and will face opposition from vested interests. ${ }^{26-28}$ In this regard, any involvement of the alcohol industry 


\section{Box 1: The SAFER initiative}

The objective of the WHO led SAFER initiative is to provide support for countries in reducing the harmful use of alcohol by enhancing the ongoing implementation of the global alcohol strategy and other WHO and UN instruments. SAFER is based on the accumulated evidence of cost effectiveness of different alcohol control measures and recognises the need to protect public health oriented policy making from alcohol industry interference as well as strong monitoring systems to ensure accountability and track progress in the implementation of the SAFER interventions.

SAFER is an acronym for the five most cost effective interventions to reduce alcohol related harm:

- Strengthen restrictions on alcohol availability

- Advance and enforce drink driving countermeasures

- Facilitate access to screening, brief interventions, and treatment

- Enforce bans or comprehensive restrictions on alcohol advertising, sponsorship, and promotion

- Raise prices on alcohol through excise taxes and pricing policies

WHO, the secretariat of the UN Interagency Task Force on the Prevention and Control of NCDs, and the UN Development Programme together with IOGT International, the NCD Alliance, the Global Alcohol Policy Alliance, and Vital Strategies have been working together to initiate and develop SAFER, engage more partners in the initiative, raise resources, and implement SAFER at country level.

Countries and development partners from governments, philanthropy, civil society, and selected private sector entities are now armed with an evidence based, action oriented programme to rally around.

in public health decisions has substantial risks with limited or no benefits. Alcohol industry activities related to marketing, education, corporate political activities, and funding of research can undermine public health efforts by hedging them against more effective interventions and distorting the research agenda. ${ }^{13} 29$ Protective systems must be put in place in the forms of guidance and enforceable codes of conduct regarding engagement. ${ }^{3031}$

\section{Conclusion}

Effective alcohol control policies have important economic and public health benefits, but their development and execution is uneven and not proportional to the harm from alcohol. Effective action will require a coordinated approach across government. In light of this, all countries will benefit from a periodic review, adjustment, and strengthening of their policies and programmes. Civil society can advocate for action, catalyse political will, and hold policy makers and government agencies to account. The alcohol industry should not be involved in the development of public health oriented government policy to reduce the harmful use of alcohol.

Over the past decade, significant progress has been made in tobacco control, largely as a result of political pressure and catalytic funding from national and international development partners. Now that countries have cost effective and feasible interventions for controlling harmful use of alcohol, it is time to accelerate action, through initiatives such as SAFER, to reduce the health and development burden from the harmful use of alcohol: people and societies everywhere will benefit.

Contributors and sources:The 14 co-authors combined represent a broad and extensive knowledge and expertise in public health research, advocacy, policy development, administration, and disease prevention and management at local, national, and international levels. DR, NB, and AK developed the first draft and all authors made extensive comments. The authors alone are responsible for the views expressed in this article and they do not necessarily represent the views, decisions, or policies of the institutions with which they are affiliated.

Competing interests: We have read and understood

Provenance and peer review: Commissioned; externally peer reviewed.

This article is part of a series proposed by the WHO Global Coordination Mechanism on NCDs and commissioned by The BMJ, which peer reviewed, edited, and made the decision to publish. Open access fees are funded by the Swiss Agency for Development and Cooperation, International Federation of Pharmaceutical Manufacturers and Associations (IFPMA), UNOPS Defeat-NCD Partnership, Government of the Russian Federation, and $\mathrm{WHO}$.

Dag Rekve, senior technical officer Nicholas Banatvala, head of secretariat ${ }^{2}$ Adam Karpati, senior vice president ${ }^{3}$ Dudley Tarlton, programme specialist ${ }^{8}$ Lucinda Westerman, policy and campaigns manager $^{4}$ BMJ policy on declaration of interests and have no relevant interests to declare.
Kristina Sperkova, president ${ }^{5}$

Sally Casswell, chair ${ }^{6}$

Maik Duennbier, director of strategy and advocacy ${ }^{5}$ Ariella Rojhani, director ${ }^{3}$

$\emptyset_{\text {ystein Bakke, secretary }}{ }^{6}$

Maristela Monteiro, senior adviser ${ }^{7}$

Natalia Linou, policy specialist ${ }^{8}$

Alexey Kulikov, external relations officer ${ }^{2}$

Vladimir B Poznyak, coordinator ${ }^{1}$

${ }^{1}$ Management of Substance Abuse, World Health Organization, Geneva, Switzerland

${ }^{2}$ United Nations Inter-Agency Task Force on the Prevention and Control of Non-communicable Diseases, World Health Organization, Geneva

${ }^{3}$ Vital Strategies, New York, USA

${ }^{4}$ NCD Alliance, Geneva, Switzerland

${ }^{5}$ IOGT International, Stockholm, Sweden

${ }^{6}$ Global Alcohol Policy Alliance, Auckland, New Zealand ${ }^{7}$ Pan American Health Organization, Washington, DC, USA

${ }^{8}$ United Nations Development Programme, New York, USA,

Correspondence to: D Rekve

rekved@who.int

\section{(c) (1)} OPEN ACCESS

This is an Open Access article distributed under the terms of the Creative Commons Attribution IGO License (https://creativecommons.org/licenses/ by-nc/3.0/igo/), which permits use, distribution, and reproduction for non-commercial purposes in any medium, provided the original work is properly cited.

\section{Check for updates}

1 GBD 2017 Causes of Death Collaborators. Global, regional, and national age-sex-specific mortality for 282 causes of death in 195 countries and territories, 1980-2017: a systematic analysis for the Global Burden of Disease Study 2017. Lancet 2018;392:1736-88. doi:10.1016/S01406736(18)32203-7

2 GBD 2016 Alcohol Collaborators. Alcohol use and burden for 195 countries and territories, 1990-

2016: a systematic analysis for the Global Burden of Disease Study 2016. Lancet 2018;392:1015-35. doi:10.1016/S0140-6736(18)31310-2

3 World Health Organization. Global status report on alcohol and health 2018. World Health Organization, 2018.

4 Karriker-Jaffe KJ, Room R, Giesbrecht N, Greenfield TK. Alcohol's harm to others: opportunities and challenges in a public health framework. J Stud Alcohol Drugs 2018;79:239-43. doi:10.15288/ jsad. 2018.79.239

5 Laslett AMRR, Waleewong O, Stanesby O, Callinan S, eds. Harm to others from drinking: patterns in nine societies. World Health Organization, (forthcoming).

6 World Health Organization. Global action plan for the prevention and control of noncommunicable diseases 2013-2020. World Health Organization, 2013.

7 United Nations. Political declaration of the third high-level meeting of the general assembly on the prevention and control of non-communicable diseases. Time to deliver: accelerating our response to address non-communicable diseases for the health and well-being of present and future generations. 2018.

8 United Nations. Sustainable development goals: 17 goals to transform our world. 
9 World Health Organization. Global strategy to reduce the harmful use of alcohol. WHO, 2010.

10 World Health Organization. Tackling NCDs: "best buys" and other recommended interventions for the prevention and control of noncommunicable diseases. WHO, 2017.

11 Poznyak V, Fleischmann A, Rekve D, Rylett M, Rehm J, Gmel G. The world health organization's global monitoring system on alcohol and health. Alcohol Res 2013;35:244-9.

12 Siegfried N, Parry C. Do alcohol control policies work? An umbrella review and quality assessment of systematic reviews of alcohol control interventions (2006 - 2017). PLoS One 2019;14:e0214865. doi:10.1371/journal.pone.0214865

13 Ferreira-Borges C, Parry CD, Babor TF. Harmful use of alcohol: a shadow over Sub-Saharan Africa in need of workable solutions. Int J Environ Res Public Health 2017;14:E346. doi:10.3390/ ijerph14040346

14 Holmes MV, Dale CE, Zuccolo L, et al, InterAct Consortium. Association between alcohol and cardiovascular disease: Mendelian randomisation analysis based on individual participant data . BMJ 2014;349:g4164. doi:10.1136/bmj.g4164

15 Millwood IY, Walters RG, Mei XW, et al, China Kadoorie Biobank Collaborative Group. Conventional and genetic evidence on alcohol and vascular disease aetiology: a prospective study of 500000 men and women in China . Lancet 2019;393:183142. doi:10.1016/S0140-6736(18)31772-0

16 Marmot M, Bell R. Social determinants and noncommunicable diseases: time for integrated action. BMJ 2019;364:l251. doi:10.1136/bmj.l251

17 Stringhini S, Carmeli C, Jokela M, et al, LIFEPATH consortium. Socioeconomic status and the $25 \times 25$ risk factors as determinants of premature mortality: a multicohort study and meta-analysis of 1.7 million men and women. Lancet 2017;389:1229-37. doi:10.1016/S0140-6736(16)32380-7

18 Manthey J, Shield KD, Rylett M, Hasan OSM, Probst C, Rehm J. Global alcohol exposure between 1990 and 2017 and forecasts until 2030: a modelling study . Lancet 2019;393:2493-502. doi:10.1016/S01406736(18)32744-2

19 United Nations. World population prospects 2017. 2017. https://population.un.org/wpp/.

20 World Health Organization. Saving lives, spending less: a strategic response to noncommunicable diseases. WHO, 2018.

21 Task Force on Fiscal Policy for Health. Health taxes to save lives. employing effective excise taxes on tobacco, alcohol, and sugary beverages, 2019.

22 Chisholm D, Moro D, Bertram M, et al. Are the "best buys" for alcohol control still valid? an update on the comparative cost-effectiveness of alcohol control strategies at the global level. J Stud Alcohol Drugs 2018;79:514-22. doi:10.15288/ jsad.2018.79.514

23 World Health Organization Regional Office for Europe. Alcohol policy implementation in the European Region. Update with 2015 data. World Health Organization, 2017.

24 Nemtsov A, Neufeld M, Rehm J. Are trends in alcohol consumption and cause-specific mortality in Russia between 1990 and 2017 the result of alcohol policy measures?J Stud Alcohol Drugs 2019;80:489-98. doi:10.15288/jsad.2019.80.489

25 Jernigan DTP. Global developments in alcohol policies: progress in implementation of the WHO global strategy to reduce the harmful use of alcohol since 2010. Background paper developed for the WHO Forum on Alcohol, Drugs and Addictive Behaviours, 26-28 June 2017. World Health Organization, 2017.

26 Bakke $\varnothing$, Endal D. Vested interests in addiction research and policy alcohol policies out of context: drinks industry supplanting government role in alcohol policies in sub-Saharan Africa. Addiction 2010;105:22-8. doi:10.1111/j.13600443.2009.02695.x

27 McCambridge J, Kypri K, Miller P, Hawkins B, Hastings G. From tobacco control to alcohol policy. Addiction 2014;109:528-9. doi:10.1111/ add. 12463

28 Babor TF. Out of Africa: three threads tying the alcohol industry to an emerging alcohol epidemic. J Stud Alcohol Drugs 2018;79:157-8. doi:10.15288/ jsad.2018.79.157

29 Babor TF, Robaina K, Brown K, et al. Is the alcohol industry doing well by "doing good"? Findings from a content analysis of the alcohol industry's actions to reduce harmful drinking. BMJ Open 2018;8:e024325. doi:10.1136/ bmjopen-2018-024325

30 McCambridge J, Daube M, McKee M. Brussels declaration: a vehicle for the advancement of tobacco and alcohol industry interests at the science/policy interface?Tob Control 2019;28:7-12. doi:10.1136/tobaccocontrol-2018-054264

31 Babor TF. Editor's corner: does alcohol industry funding corrupt alcohol science? A startling revelation about the early history of JSAD . J Stud Alcohol Drugs 2017;78:173-4. doi:10.15288/ jsad.2017.78.173

Cite this as: BMJ 2019;367:16162

http://dx.doi.org/10.1136/bmj.l6162 